\title{
Preparation of a Cube-Textured Ni-7at.\%W Based Template Used for Coated Conductors
}

\author{
Xu Zhao, Yuxin Zheng, Fangyuan Zhang, Mangmang Gao* \\ Ningxia University, Yinchuan, China \\ Email: `gaomm@nxu.edu.cn
}

How to cite this paper: Zhao, X., Zheng, Y.X., Zhang, F.Y. and Gao, M.M. (2021) Preparation of a Cube-Textured Ni-7at.\%W Based Template Used for Coated Conductors. Materials Sciences and Applications, 12, 255-262.

https://doi.org/10.4236/msa.2021.126017

Received: March 1, 2021

Accepted: June 18, 2021

Published: June 21, 2021

Copyright () 2021 by author(s) and Scientific Research Publishing Inc. This work is licensed under the Creative Commons Attribution International License (CC BY 4.0).

http://creativecommons.org/licenses/by/4.0/

\section{(c) (i) Open Access}

\begin{abstract}
Although Ni-W substrate with high W content (>5at.\%) substrates have been developed successfully, the quality of cube texture and grain boundary, as well as extensive applications in coated conductors should be further improved. In the present work, once intermediate annealing treatment (IAT) at $500^{\circ} \mathrm{C}$ for $2 \mathrm{~h}$ has been employed to optimize the deformation and recrystallization textures in Ni-7at.\%W (Ni7W) substrates. As a result, competitive high cube texture content $\left(<10^{\circ}\right)$ and low angle grain boundary fraction $\left(<10^{\circ}\right)$ were realized (98.5\% and $91.2 \%$, respectively). $\mathrm{A} \mathrm{Gd}_{2} \mathrm{Zr}_{2} \mathrm{O}_{7}$ (GZO) buffer layer with strong cube texture and high-quality surface deposited successfully on the Ni7W substrate using the chemical solution deposition method, demonstrating the advanced $\mathrm{GZO} / \mathrm{Ni} 7 \mathrm{~W}$ template is promising for coated conductors.
\end{abstract}

\section{Keywords}

NiW Substrate, Texture, $\mathrm{Gd}_{2} \mathrm{Zr}_{2} \mathrm{O}_{7}$ Buffer Layer, Coated Conductors

\section{Introduction}

$\mathrm{Ni}-\mathrm{W}$ alloys are considered as the most promising substrate materials for high temperature superconducting $\mathrm{YBa}_{2} \mathrm{Cu}_{3} \mathrm{O}_{7-\delta}(\mathrm{YBCO})$ coated conductors in terms of rolling assisted biaxial textured substrates (RABiTS) technique [1] [2] [3]. Although over 100-m-long Ni-5at.\%W (Ni5W) flexible textured substrates have been prepared commercially, Ni-W substrates with high tungsten content $(>5 \%)$ could provide higher strength and acceptable magnetic properties. Up to now, the textured Ni-7 9.5at.\%W (Ni7 9.5W) alloy substrates have been developed using both powder metallurgy [4] [5] and melting routes [6]-[14]. Since the reduction of stacking fault energy in Ni-W alloy with high tungsten additions, several specific rolling techniques, in particular, the intermediate annealing 
treatment (IAT), have been applied to produce cube texture in such $\mathrm{Ni}-\mathrm{W}$ substrates. Gaitzsch et.al reported that a sharp textured Ni-9.5at.\%W substrate with cube texture content of $96 \%$ (deviated from ideal cube orientation within $10^{\circ}$ ) was achieved in terms of the IAT rolling technique [9]. However, this result is not somewhat equivalent to the commercial Ni5W substrate. Thus, more attention should be still paid to fabricating Ni-W alloy ( $>5$ at.\%W) substrates, especially on the Ni7W substrate which is easier to realize cube texture than the Ni9W substrate, based on the attracting IAT rolling technique.

Recently, a series of work [15] [16] [17] [18] have been focused on the epitaxial growth of $\mathrm{Gd}_{2} \mathrm{Zr}_{2} \mathrm{O}_{7}$ (GZO) buffer layer on Ni5W substrates by means of chemical solution deposition (CSD) method. A promising critical current density $J_{c}$ of $2.2 \mathrm{MAcm}^{-2}$ at $77 \mathrm{~K}$ in $\mathrm{YBCO}$ superconducting layer based on $\mathrm{YBCO} /$ $\mathrm{Ce}_{0.9} \mathrm{La}_{0.1} \mathrm{O}_{2} / \mathrm{GZO} / \mathrm{NiW}$ architecture has been achieved, using an all-CSD route [17]. In this case, the commercial $\mathrm{Ni} 5 \mathrm{~W}$ tapes were employed as textured substrates. Thus, it is imperious to verify the feasibility of the Ni7W substrate for the deposition growth of the advanced mentioned buffer layer architecture, which has not been grown on the textured NiW substrates with high W contents (>5at.\%).

In the present work, the strong cube-textured Ni7W substrate was fabricated firstly, using once IAT rolling technique with intermediate annealing at $500^{\circ} \mathrm{C}$. Subsequently, a GZO buffer layer was epitaxially grown on the as-obtained Ni7W substrate by CSD method. The crystallographic texture of substrate and the quality of GZO film have been characterized.

\section{Experimental Details}

Electrolytic nickel pieces (99.95\%) and W bulks (99.99\%) were melted and then casted into a cylindrical ingot in an induction furnace. After hot forging and hot rolling, the Ni7W rods were cold rolled by applying a 5\% reduction per pass to a final thickness of $90 \mu \mathrm{m}$, corresponding to a total reduction of $99 \%$. For comparison, the other sample was annealed at $500^{\circ} \mathrm{C}$ for $2 \mathrm{~h}$ after cold rolling to $90 \%$ degree followed by further cold rolling to $90 \mu \mathrm{m}$, named as the IAT rolling technique. The explanation on optimum IAT parameters would be discussed systematically as another issue elsewhere. The rolled Ni7W tapes were annealed at $1200^{\circ} \mathrm{C}$ in a flowing $\mathrm{Ar}-4 \% \mathrm{H}_{2}$ atmosphere to obtain the cube orientation. The textured Ni7W substrate was coated with a GZO buffer layer prepared using a propionic acid-based CSD route. The total cation concentration of the GZO precursor solution was $0.6 \mathrm{~mol} / \mathrm{L}$ and the pulling speed for dip-coating was 20 $\mathrm{mm} / \mathrm{min}$. For crystallization of the buffer layer, the sample was held at $1050^{\circ} \mathrm{C}$ for $30 \mathrm{~min}$ in a quartz tube furnace, in $\mathrm{Ar}-4 \% \mathrm{H}_{2}$ gas flowing as well. The deformation texture of the substrate and coating layer was characterized by a Bruker D8 X-ray goniometer with $\mathrm{Cu} \mathrm{Ka}$ radiation. Electron Backscattered Diffraction (EBSD) measurements were carried out using a scanning electron microscope (SEM, Zeiss Supra 35, equipped with a detector from HKL technology). The surface morphologies of the film were evaluated by the same SEM setup, and 
the surface roughness was analyzed by atomic force microscope (AFM, MicroNano D5A).

\section{Results and Discussion}

Figure 1 shows the (111) pole figures of the Ni7W substrates without and with IAT rolling, respectively. Clearly, all of the (111) pole figures reveal the typical characteristics of deformation texture for metal alloys with medium stacking fault energy, i.e., they contain both the Brass-type deformation texture and the Copper-type deformation texture. It also can be seen that the intensity of the Copper-type deformation texture in the IAT sample is stronger than that in cold rolled sample. Meanwhile, the volume fractions of copper (C) and S orientation increase in the IAT sample, whereas the brass $(\mathrm{Br})$ orientation decreases (see Table 1). This is due to the stress relief during IAT annealing, which increases the ability of deformation slipping and transfers the deformation texture from brass-type to copper-type [11]. Meanwhile, the volume fraction of Goss orientation increases slightly from $7.81 \%$ to $9.42 \%$ in the IAT substrate, which is probably resulted from the recovery occurring at $500^{\circ} \mathrm{C}$. Additionally the cube orientation is no obvious change after the IAT. Consequently, the IAT rolling is beneficial for the formation of copper-type deformation texture in the Ni7W metallic alloy.

The Ni7W substrate with enhanced copper-type deformation texture has been realized a sharp cube texture upon recrystallization, where the area fraction of cube grains deviating from the exact $\{100\}<001>$ orientation within $10^{\circ}$ amounts to $98.5 \%$ (see Figure 2(a)). However, the fraction in a traditional coldrolled Ni7W substrate is only $71.8 \%$. Four sharp poles and a weak background intensity are visible from the (111) three-dimensional pole figure (Figure 2(e)), which demonstrates again a high degree of cube texture in the IAT Ni7W substrate. In parallel, the length fraction of low angle grain boundaries (LAGB) within a misorientation angle below $10^{\circ}$ reaches $91.2 \%$ (Figure $2(\mathrm{c})$ ). Although twin boundaries are still evident (merely $2 \%$ ), the high density of LAGB with misorientation angle less than $4^{\circ}$ (Figure $2(\mathrm{~d})$ ) could ensure a high critical current density in YBCO layer [19]. These results on cube texture and LAGB show that the prepared Ni7W substrate could be equivalent to those of commercial Ni5W substrates, whereas the magnetic and mechanical properties have been improved due to the higher $\mathrm{W}$ addition.

Figure 3(a) shows the microstructure of the GZO film grown on the Ni7W

Table 1. Volume fractions of deformation orientations in two substrates calculated using the orientation distribution function. The threshold angle deviated from ideal orientation is $15^{\circ}$.

\begin{tabular}{ccccc}
\hline & Brass $\left(<15^{\circ}\right) \%$ & Copper $\left(<15^{\circ}\right) \%$ & $\mathrm{~S}\left(<15^{\circ}\right) \%$ & Goss \\
\hline CR & 37.71 & 11.68 & 34.25 & 7.81 \\
With IAT & 29.63 & 13.91 & 39.23 & 9.42 \\
\hline
\end{tabular}




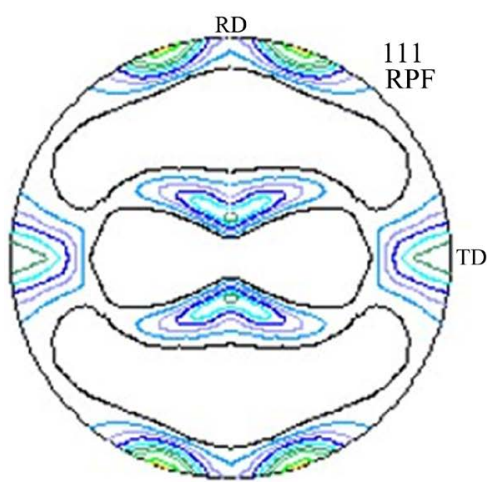

(a)

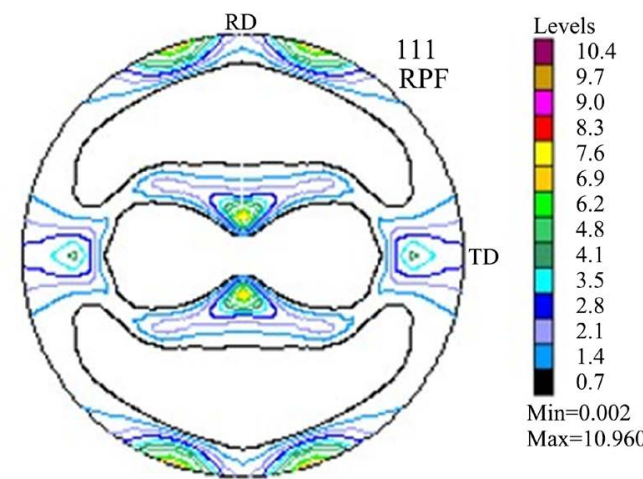

(b)

Figure 1. (111) pole figures of Ni7W substrates without (a) and with (b) IAT rolling.

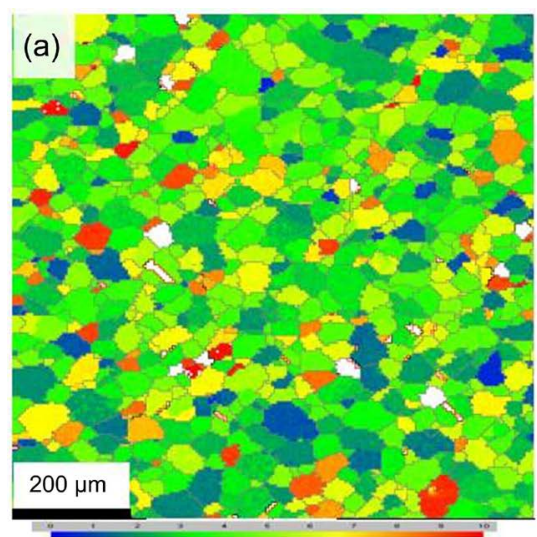

(c)

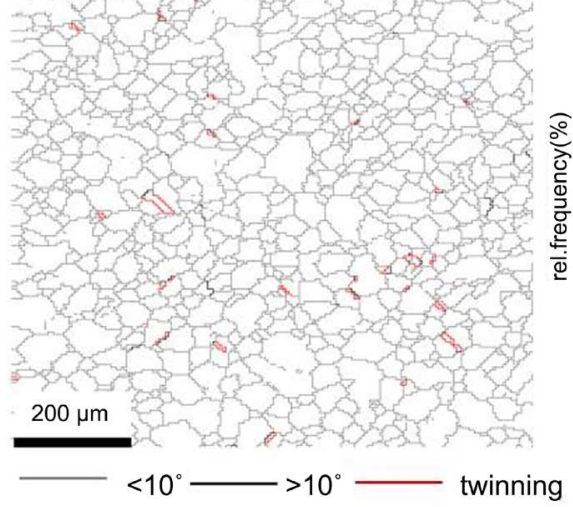

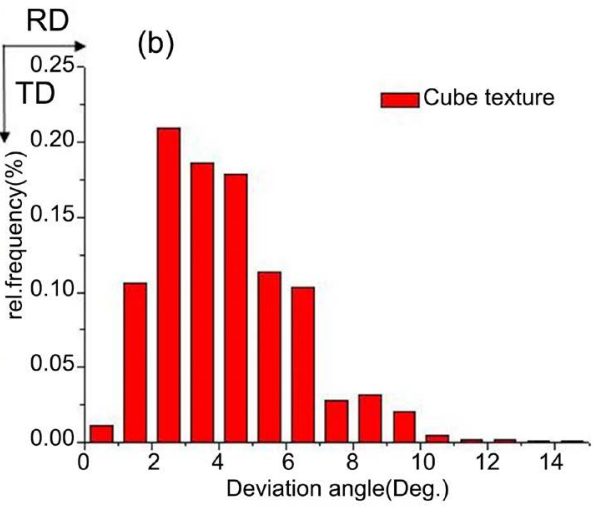

(d)

(e)

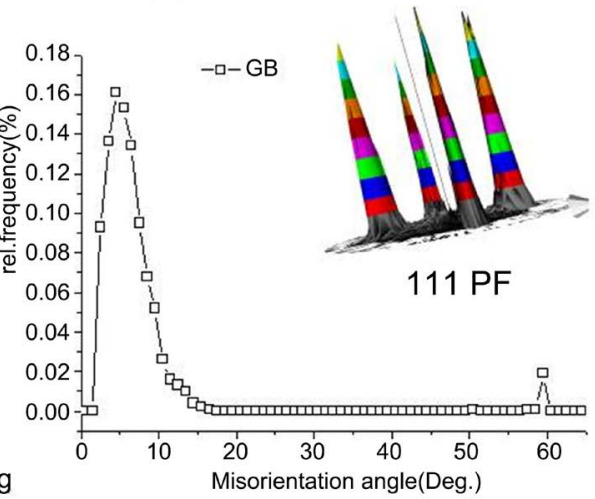

Figure 2. (a) EBSD map of $90-\mu \mathrm{m}$-thick Ni7W tape with IAT rolling after recrystallization at $1200^{\circ} \mathrm{C}$ for $1 \mathrm{~h}$. The measuring area is $800 \times 800 \mu \mathrm{m}^{2}$, with a step size of $1 \mu \mathrm{m}$; (b) Cube texture deviated from the ideal orientation; (c) Grain boundary map, where misorientaions between $2^{\circ}$ and $10^{\circ},>10^{\circ}$ and twin boundaries are indicated by grey lines, black lines and red lines, respectively; (d) Grain boundary distribution curve; (e) Threedimensional (111) pole figure calculated from X-ray diffraction.

substrate. The GZO grain size is approximately $20 \mathrm{~nm}$, and the film thickness is about $30 \mathrm{~nm}$. The film is smooth, continuous and crack-free. No apparent grain size and shape variation is visible in the film. Promising results could be observed from that the film is homogeneous as growing across the grain boundaries 


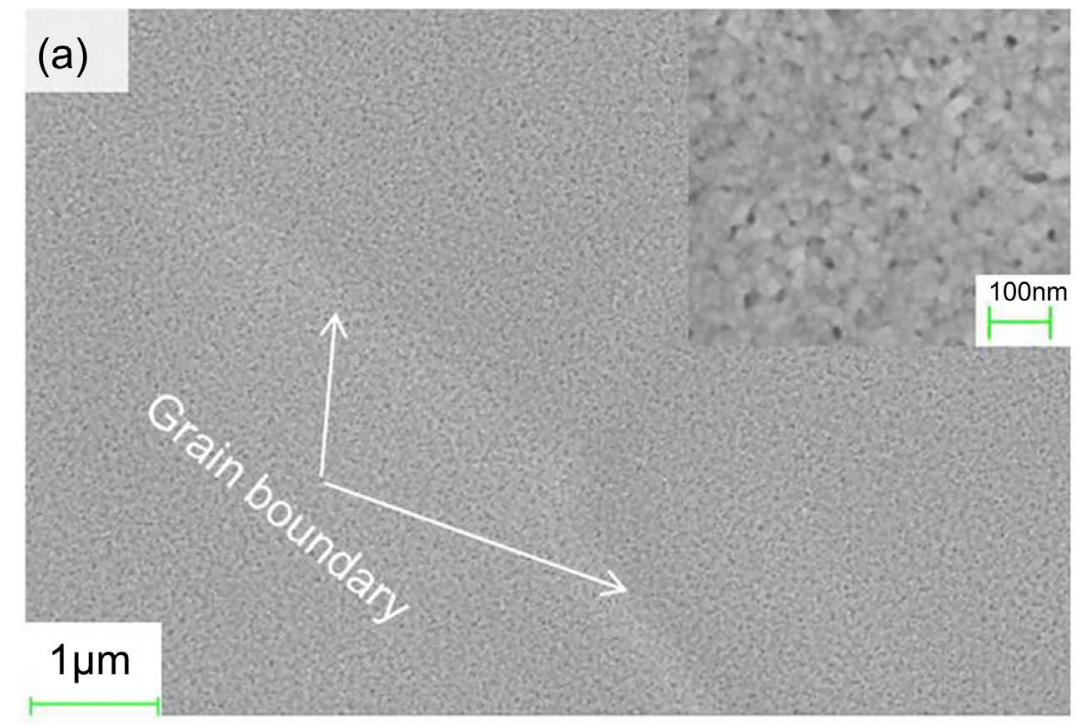

(b)
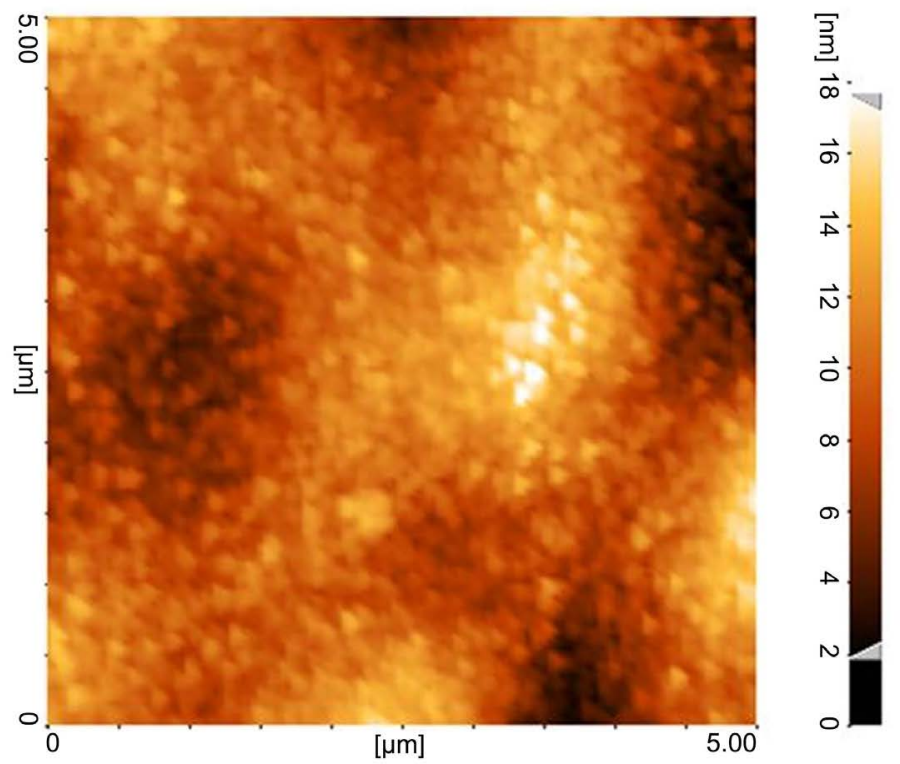

Figure 3. GZO buffer layer deposited on Ni7W substrate tapes: (a) SEM morphology. Inset: high resolution image with $200 \mathrm{~K}$ magnification; (b) AFM image, scanning area is 5 $\mu \mathrm{m} \times 5 \mu \mathrm{m}$.

of the Ni7W substrate (shown in Figure 3(a)). The AFM result shows that the root mean square roughness is $2.6 \mathrm{~nm}$ (Figure $3(\mathrm{~b})$ ). A strong $\{001\}<100>$ texture was obtained in the film. The full width at half maximum (FWHM) values for the (222) $\varphi$-scan and the (004) $\omega$-scan are $5.95^{\circ}$ and $6.33^{\circ}$, respectively, demonstrating slight improvement of cube texture compared with that of Ni7W substrate (see Table 2). The quality of present grown GZO film is almost identical to that in [17], where a high $J_{c}$ of $2.2 \mathrm{MAcm}^{-2}$ in YBCO layer has been achieved employing GZO as buffer layer. Thus, it could be concluded that the high quality GZO film deposited on Ni7W substrates produced by once IAT rolling with optimum annealing parameters provides a promising GZO/Ni7W template for further deposition of buffer and superconducting layers. 
Table 2. FWHM values $\left(^{\circ}\right.$ ) for recrystallized Ni7W substrate and $\mathrm{Ga}_{2} \mathrm{Zr}_{2} \mathrm{O}_{7}$ film.

\begin{tabular}{ccc}
\hline Materials & $\varphi$-scan & $\omega$-scan \\
\hline $\mathrm{Ni7W}$ & 6.07 & 6.77 \\
$\mathrm{Ga}_{2} \mathrm{Zr}_{2} \mathrm{O}_{7}$ & 5.95 & 6.33 \\
\hline
\end{tabular}

\section{Conclusion}

More copper-type deformation texture was formed in the cold-rolled Ni7W substrate prepared by once IAT rolling, resulting in a strong cube texture in substrates upon recrystallization. The fraction of cube orientation $\left(<10^{\circ}\right)$ is $98.5 \%$, and the length fraction of low angle grain boundaries $\left(<10^{\circ}\right)$ reaches $91.2 \%$. These values are comparable with that of commercial Ni5W substrates. Furthermore, a $\mathrm{Ga}_{2} \mathrm{Zr}_{2} \mathrm{O}_{7}$ buffer layer has been deposited successfully on the substrate using CSD method. The strong cube texture, as well as the high surface quality of $\mathrm{Ga}_{2} \mathrm{Zr}_{2} \mathrm{O}_{7}$ film, demonstrates that the $\mathrm{GZO} / \mathrm{Ni} 7 \mathrm{~W}$ template has been successfully grown, supporting further deposit the $\mathrm{CeO}_{2}$ layer and $\mathrm{YBCO}$ superconducting layers.

\section{Acknowledgements}

The authors gratefully acknowledge financial support from National Natural Science Foundation of China (NSFC Grant No. 51509016).

\section{Conflicts of Interest}

On behalf of all authors, the corresponding author states that there is no conflict of interest.

\section{References}

[1] Sathyamurthy, S., Paranthaman, M., Zhai, H.Y., Kang, S., Aytug, T., Cantoni, C., Leonard, K.J., Payzant, E.A., Christen, H.M., Goyal, A., Li, X., Schoop, U., Kodenkandath, T. and Rupich, M.W. (2004) Chemical Solution Deposition of Lanthanum Zirconate Barrier Layers Applied to Low-Cost Coated-Conductor Fabrication. Journal of Materials Research, 19, 2117-2123. https://doi.org/10.1557/JMR.2004.0281

[2] Zhang, W., Rupich, M.W., Schoop, U., Verebelyi, D.T., Thieme, C.L.H., Li, X., Kodenkandath, T., Huang, Y., Siegal, E., Buczek, D., Carter, W., Nguyen, N., Schreiber, J., Prasova, M., Lynch, J., Tucker, D. and Fleshler, S. (2007) Progress in AMSC Scale-Up of Second Generation HTS Wire. Physica C: Superconductivity and its Applications, 463-465, 505-509. https://doi.org/10.1016/j.physc.2007.04.239

[3] Eickemeyer, J., Selbmann, D., Opitz, R., De Boer, B., Holzapfel, B., Schultz, L. and Miller, U. (2001) Nickel-Refractory Metal Substrate Tapes with High Cube Texture Stability. Superconductor Science and Technology, 14, 152-159. https://doi.org/10.1088/0953-2048/14/3/306

[4] Zhou, Y.X., Ghalsasi, S.V., Hanna, M., Tang, Z.J., Meng, R.L. and Salama, K. (2007) Fabrication of Cube-Textured Ni-9at.\%W Substrate for YBCO Superconducting Wires Using Powder Metallurgy. IEEE Transactions on Applied Superconductivity, 17, 3428-3431. https://doi.org/10.1109/TASC.2007.899486

[5] Gao, M.M., Suo, H.L., Zhao, Y., Zhu, Y.H., Ma, L., Fan, R.F., Liu, M. and Zhou, 
M.L. (2009) Investigation of Texture Formation in Ni-7at.\%W Alloy Substrates by Spark Plasma Sintering Technique. IEEE Transactions on Applied Superconductivity, 19, 3279-3281. https://doi.org/10.1109/TASC.2009.2017881

[6] Eickemeyer, J., Huhne, R., Guth, A., Rodig, C., Klauß, H. and Holzapfel, B. (2008) Textured Ni-7.5 at.\%W Substrate Tapes for Coated Conductors. Superconductor Science and Technology, 21, Article ID: 105012. https://doi.org/10.1088/0953-2048/21/10/105012

[7] Gaitzsch, U., Eickemeyer, J., Rodig, C., Freudenberger, J., Holzapfel, B. and Schultz, L. (2010) Paramagnetic Substrates for Thin Film Superconductors: Ni-W and NiW-Cr. Scripta Materialia, 62, 512-515. https://doi.org/10.1016/j.scriptamat.2009.12.030

[8] Eickemeyer, J., Huhne, R., Guth, A., Rodig, C., Gaitzsch, U., Freudenberger, J., Schultz, L. and Holzapfel, B. (2010) Textured Ni-9.0 at.\%W Substrate Tapes for YBCO-Coated Conductors. Superconductor Science and Technology, 23, Article ID: 085012. https://doi.org/10.1088/0953-2048/23/8/085012

[9] Gaitzsch, U., Hanisch, J., Huhne, R., Rodig, C., Freudenberger, J., Holzapfel, B. and Schultz, L. (2013) Textured Ni-9.0 at.\%W Substrate Tapes for YBCO-Coated Conductors. Superconductor Science and Technology, 26, Article ID: 085024. https://doi.org/10.1088/0953-2048/26/8/085024

[10] Gao, M.M., Suo, H. L., Grivel, J.-C., Zhao, Y., Gao, P.K., Liu, M. and Ma, L. (2011) Fabrication of the Textured Ni-9.3at.\%W Alloy Substrate for Coated Conductors. IEEE Transactions on Applied Superconductivity, 21, 2969-2972. https://doi.org/10.1109/TASC.2011.2105850

[11] Yu, H. and Liu, W. (2011) Fabrication of the Textured Ni-9.3at.\%W Alloy Substrate for Coated Conductors. Materials Science and Technology, 27, 1412-1215.

[12] Liu, J.N., Liu, W., Tang, G.Y. and Zhu, R.F. (2014) Influence of Intermediate Annealing on the Microstructure and Texture of Ni-9.3 at.\%W Substrates. International Journal of Minerals, Metallurgy, and Materials, 211, 162-168. https://doi.org/10.1007/s12613-014-0880-2

[13] Liu, J.N., Liu, W., Tang, G.Y. and Zhu, R.F. (2014) Fabrication of Textured Ni-9.3 at.\%W Substrate by Electropulsing Intermediate Annealing Method. Physica C, 497, 119-112. https://doi.org/10.1016/j.physc.2013.12.001

[14] Liang, Y.R., Tian, H., Suo, H.L., Wang, P., Meng, Y.C., Ma, L. and Liu, M. (2015) Recrystallization and Cube Texture Formation in Heavily Cold-Rolled Ni7W Alloy Substrates for Coated Conductors. Journal of Materials Research, 30, 1686-1692. https://doi.org/10.1557/jmr.2015.92

[15] Zhao, Y., Grivel, J.-C., Napari, M., Pavlopoulos, D., Bedanrcik, J. and Von Zimmermann, M. (2012) Highly Textured $\mathrm{Gd}_{2} \mathrm{Zr}_{2} \mathrm{O}_{7}$ Films Grown on Textured Ni5at\%W Substrates by Solution Deposition Route: Growth, Texture Evolution and Microstructure Dependency. Thin Solid Films, 520, 1965-1972.

https://doi.org/10.1016/j.tsf.2011.09.072

[16] Zhang, X., Xia, Y.D., Ke, C., Cheng, C.H., Zhang, Y. and Zhao, Y. (2016) Preparation of $\mathrm{Gd}_{2} \mathrm{Zr}_{2} \mathrm{O}_{7}$ Buffer Layers for Coated Conductor by Polymer-Assisted Chemical Solution Deposition. Materials Letters, 178, 132-134.

https://doi.org/10.1016/j.matlet.2016.04.015

[17] Zhao, Y., Ma, L., Wu, W., Suo, H.L. and Grivel, J.-C. (2015) Study on Advanced $\mathrm{Ce}_{0.9} \mathrm{La}_{0.1} \mathrm{O}_{2} / \mathrm{Gd}_{2} \mathrm{Zr}_{2} \mathrm{O}_{7}$ Buffer Layers Architecture Towards all Chemical Solution Processed Coated Conductors. Journal of Materials Chemistry A, 3, 13275-13282. https://doi.org/10.1039/C5TA00153F 
[18] Zhao, Y., Opata, Y.A., Wu, W. and Grivel, J.-C. (2017) Surface Defects on the $\mathrm{Gd}_{2} \mathrm{Zr}_{2} \mathrm{O}_{7}$ Oxide Films Grown on Textured NiW Technical Substrates by Chemical Solution Method. Materials Characterization, 124, 58-64.

https://doi.org/10.1016/j.matchar.2016.12.012

[19] Fernandez, L., Holzapfel, B., Schindler, F., De Boer, B., Attenberger, A., Hanisch, J. and Schultz, L. (2003) Influence of the Grain Boundary Network on the Critical Current of $\mathrm{YBa}_{2} \mathrm{Cu}_{3} \mathrm{O}_{7}$ Films Grown on Biaxially Textured Metallic Substrates. Physical Review B, 67, Article ID: 052503.

https://doi.org/10.1103/PhysRevB.67.052503 